\title{
POVO OU MULTIDÕES? 1
}

\author{
Tradução de Cláudia Muller Sachs ${ }^{2}$
}

Resumo

Discussão sobre os conceitos de povo ou multidão quer do ponto de vista das implicações políticas quanto éticas e estéticas que albergam. Legitimidade e desqualificação, identidade e deslocamento, produção e consumo são alguns dos temas debatidos, à luz das considerações éticas que devem presidir tais enfoques.

Palavras-chave: povo, multidão, movimentos de massas.

\begin{abstract}
Discussion on the concepts of people or crowd from the point of view of political implications as well as the ethics and aesthetics involved. Disqualification and legitimacy, identity and displacement, production and consumption are among the topics discussed in the light of ethical considerations that should govern such approaches.
\end{abstract}

Keywords: people, multitude, social mass movement.

Respondendo a uma pergunta de Eric Alliez sobre o uso que faz do conceito de povo e sobre o interesse em substituí-lo por multidão, Jacques Rancière lembra que o conceito de povo é, de fato, constitutivo do político, posto ser o nome genérico do conjunto de processos de subjetivação que questiona as representações da igualdade. A política é sempre um povo contra outro. O pensamento das multidões, pela fobia que manifesta em relação a uma política que se definiria negativamente, rejeita a negativa. O conceito de multidão opõe àquele de povo o pedido para que a política não seja mais uma esfera separada. Os sujeitos políticos deveriam expressar o múltiplo que seria a Lei do ser. De fato, o conceito de multiplicidade inscreve-se na expansão daquele de forças produtivas. Mas pensar em multidões não escapa às alternativas que o pensamento dos sujeitos políticos geralmente encontram.

${ }^{1}$ Entrevista a Eric Alliez. Multitudes, junho 2002.

${ }^{2}$ Mestre em Teatro e doutoranda do Programa de Pós-Graduação em Teatro da UDESC. 
Multidões: Em La Mésentente (O desentendimento, Galiléia, 1995), o senhor propõe a análise do conflito entre a identificação policial da comunidade (determinando lugares e seções em função de identidades) e a subjetivação política abrindo "mundos singulares da comunidade", produtores de novos campos de experiência a partir de "sujeitos flutuantes que rompem toda representação de lugares e de seções", perturbando "a homogeneidade do sensível”, etc... Longe de expressar esse conflito em termos de multidões plurais contra o povo reunido (soberania popular reduzida à representação), é ao "povo” que o senhor outorga o que chama de "traço igualitário" constitutivo da ação política enquanto "construção local e singular de casos de universalidade". Além de uma questão de escrita, algumas reflexões o inspiram nas tentativas apresentadas em ajuntar em torno da noção biopolítica de multidões a. a descrição "fenomenológica" dos movimentos antiglobalização e b. a determinação "ontológica" dos processos contemporâneos de ruptura com a ordem capitalista do mundo?

Jacques Rancière: Povo ou multidões? Antes de saber qual palavra ou conceito é preferível, devemos saber o que é o conceito. Povo é para mim o nome de um sujeito político, isto é, um suplemento em relação a toda lógica de contagem da população, de suas partes e seu todo. Isso significa um desvio em relação a qualquer ideia de povo como soma de partes, corpo coletivo em movimento, corpo ideal encarnado na soberania, etc. Eu o compreendo no sentido de "nós somos o povo" dos manifestantes de Leipzig, que manifestamente não eram povo, mas operavam o discurso perturbador da incorporação estatal. Povo, nesse sentido, é para mim o nome genérico para o conjunto dos processos de subjetivação que produzem o efeito de traço igualitário ao questionar as formas de visibilidade do comum e as identidades, afiliações, partilhas, etc... que definem: este processo pode pôr em jogo todos os tipos de nomes singulares, consistentes ou inconsistentes, "sérios" ou paródicos. Isso significa também que tais processos põem em cena a política como artifício da igualdade, o que não é nenhum fundamento "real", só existindo como condição ativa posta em ato em todos esses dispositivos de conflito. O interesse do denominativo povo, para mim, é o de por em cena a ambiguidade. A política, neste sentido, é a discriminação ativa daquilo que, em última análise, insere-se sob o nome de povo: a operação de diferenciação que estabelece coletivos políticos ao acionar a inconsistência igualitária ou a operação identitária que impõe a política sobre os proprietários dos corpos sociais ou a ilusão dos corpos gloriosos da comunidade. A política é sempre um povo sobre outro, um povo contra o outro.

Talvez seja isso o que o pensamento das multidões rejeita. A oposição do molar ao molecular, ou do paranóico ao esquizofrênico dificulta, sem 
dúvida, a compreensão. O problema não é que o povo é demasiado molar, demasiado tomado pelas fantasias do Um. O problema é que ele consiste na singularidade de sua divisão, no fato de que a política seja uma esfera particular, um conjunto de ações e de enunciações específicas. Na mente das multidões há a fobia do negativo, de uma política que se define "contra”, mas também aquela que é apenas política, isto é, fundada na inconsistência do traço igualitário e na construção arriscada em seus assuntos de efetividade. Antes de ser a recusa da estrutura paranóica da oposição dual, a parte valorizada das multidões é valorizada pelo sujeito da ação política que não esteja marcado por nenhuma separação, um sujeito "comunista", no sentido em que refuta toda particularidade de dispositivos e esferas de subjetivação. Comunista também no sentido de que o que nele age é o poder daquilo que faz existir seres em comum. $\mathrm{O}$ conceito de multidão opõe àquele de povo o pedido comunista: que a política não seja uma esfera separada, que tudo seja político, quer dizer, na verdade, que a política expressa a natureza do todo, a natureza do não separado: que a comunidade esteja baseada na própria natureza do ser coletivo, no poder corriqueiro que coloca a comunidade entre os indivíduos em geral.

Se "multidão" separa-se de "povo", o faz através desta reivindicação ontológica que substancializa o pressuposto igualitário: para não se constituir como oposição, como reação, a política deve ter seu princípio e seu telos numa coisa que não ela mesma. Os sujeitos políticos devem expressar o múltiplo que é a própria lei do ser. Aqui, pensar a multidão inscreve-se na tradição da filosofia política, que busca devolver a excepcionalidade política como princípio que insere os seres em comunidade. Mais especificamente, esse pensamento se inscreve na tradição metapolítica própria à idade moderna da filosofia política: é característica da metapolítica conclamar precários artifícios da cena política à verdade do poder imanente que põe os seres em comunidade e identificar a verdadeira comunidade com a efetividade inclusiva e sensível desta verdade. O paradoxo metapolítico reside no fato de que a afirmação do poder comum se identifica com a verdade do ser indesejado da comunidade, do ser não desejado do Ser. Querer a comunidade, segundo a metapolítica moderna, é querê-la conforme o indesejado que é a própria substância do Ser. A questão para mim é saber se o que "funda" a política não é, exatamente, o que a torna impossível. $\mathrm{O}$ que a ontologia indica como forma de agir tem como nome verdadeiro a ética: querer o indesejado é, por excelência, o que proclama a ética de Nietzsche ou Deleuze do Eterno retorno, que afirma o acaso e escolhe o que foi, a ética do futuro opondo o e...e... os agenciamentos múltiplos ao ... ou...ou... as vontades ativas que... de futuros opondo-os e... e os arranjos múltiplos para, ou ... ou... as vontades de agir que perseguem seus fins contra outros fins.

Para que os futuros múltiplos se substancializem em multidões, é necessária outra coisa: não basta que o Ser seja afirmação, é necessário que tal 


\section{Urdimento}

${ }^{3}$ HARDT, M.; NEGRI, A. Império, Harvard University Press, 2000, p.60.

${ }^{4}$ Ibid., p.394. afirmação seja o conteúdo imanente ao de toda negação, é necessário que a ostentação do Ser sem vontade não seja deixada às conexões do acaso e às suas contra-realizações, mas que seja habitada por uma teleologia imanente. "Multidões" é o nome de um tal poder de ser superabundante que se identifica com a essência da comunidade, mas também é o responsável pela sua própria superabundância em derrubar barreiras à sua realização como uma comunidade sensível. Se a negatividade dos sujeitos políticos deve ser revogada, é necessário que o poder de afirmação seja um poder perturbador, instalado em todas as instâncias de dominação como seu conteúdo último e um conteúdo destinado a quebrar as barreiras. Precisamos que as "multidões" sejam o conteúdo, cujo Império é o possuidor.

Esse poder de afirmação perturbador, poder afirmativo e final daquele que está "sem vontade", recebeu nome na teoria marxista: chamam-se forças produtivas. O nome tem má reputação. "Produtivo" e "produção" são suspeitos de recordar uma época obsoleta e ultrapassada da fábrica e do partido, juntamente com uma ética do trabalho redutora em relação ao poder coletivo do pensamento e da vida que quer expressar "multidões”. Muitas discussões de Multidões testemunham tal dificuldade. Mas o conteúdo particular que lhe damos para a produção tem pouca importância. O conceito de produção é muito amplo, incluindo quaisquer coisas como forças produtivas, inclusive a preguiça e a recusa ao trabalho. O ponto fundamental é a determinação de existir do coletivo como produção, é a ideia de produção como uma força habitada por uma teleologia imanente à sua essência afirmativa. Os autores de Império podem apelar à "multidão plural de subjetividades produtivas e criadoras da globalização", ao "movimento perpétuo", às "constelações de singularidades" que elas formam, a seus "processos de mistura e hibridação" que não podem ser rebaixados a nenhuma simples lógica de correspondência entre o sistêmico e o a-sistêmico ${ }^{3}$. Essa latitude deixada às hibridações múltiplas conta menos que a segurança trazida pelo conceito em si: a garantia de que estes acordos produtivos são a realidade do próprio Império, de que são as lutas da multidão que "produziram o próprio Império como inversão de sua própria imagem”, da maneira como, mais uma vez, o homem feuerbachiano construiu seu deus e poderá retomar seus atributos para uma vida plenamente humana. O essencial é a afirmação metapolítica de uma verdade do sistema dotada de efetividade própria. A relutância em relação ao ideal "produtivo" apenas atesta a lacuna existente entre o conceito ontológico de produção e seus avatares empíricos.

Essa lacuna é também a liberdade de ação oferecida para reformular a afirmação "produtivista” diante destas aporias. Neste sentido, o conceito de "multidões" inscreve-se na grande empreitada de ampliação do conceito de "forças produtivas" que marcou a teoria e os movimentos marxistas na segunda metade do século XX. O marxismo clássico tendia a fazer das forças 
produtivas o poder da verdade capaz de dissipar as sombras políticas. O leninismo foi a ruptura dessa visão, a necessidade declarada e praticada do ato arqui-político que realizasse para efetuar o trabalho que as forças produtivas tiveram que realizar. A falência desta arqui-política engendrou essa terceira época do marxismo, que não quis mais opor a verdade econômica à aparência política, ou a decisão revolucionária ao fatalismo econômico, mas integrar no conceito de forças produtivas o conjunto dos procedimentos que, de uma forma ou de outra, formam a coletividade: a atividade científica e técnica ou a atividade intelectual criadora em geral à prática política e a todas as formas de resistência ou fuga à ordem vigente do mundo. A teoria revisionista da "ciência força produtiva direta” e da Revolução Cultural, a revolução estudantil e o obreirismo foram as várias formas deste projeto que o conceito de multidões tenta hoje radicalizar: deixar qualquer manifestação da atividade transformadora de um estado de coisas sob a responsabilidade das forças produtivas, isto é, baixo a responsabilidade da lógica do conteúdo que não pode deixar de explodir o invólucro. Neste sentido, o enunciado metapolítico "tudo é político" é exatamente idêntico ao enunciado "tudo é econômico", idêntico, em última análise, ao enunciado arqui-político "todo pensamento assume um risco” que podemos traduzir como "todo risco é uma força produtiva”.

A parte que as multidões deixam ao acaso conta menos, então, que a identificação do acaso em si à necessidade, o anti-produtivismo menos que sua integração na única oposição interna do Império - ou seja, no final das contas o Capital - às forças que ele "desencadeia”. O ponto de força essencial - assim como o ponto de fragilidade essencial - é a afirmação dessa cena "imperial" como cena única. Pensar em multidões é querer assumir a dimensão de um mundo efetivamente globalizado, contra um povo ainda apegado aos Estadosnação. A ambição é justa se ela não esquecer que - globalização ou não - há hoje o dobro de Estados-nação, o dobro do número de núcleos militares, policiais, etc...que há cinquenta anos. Ela é correta se não consagrar a título de "nomadismo" a realidade dos deslocamentos maciços de populações que são consequência do poder repressivo dos Estados-nação. A exaltação destes movimentos nômades que "ultrapassam e quebram os limites do equilíbrio" e criam novo espaços "descritos" pelas topologias incomuns, pelos rizomas subterrâneos e impossíveis de conter" faz, de modo entusiasta, a mesma operação que realizou, de modo compassivo, o fotógrafo que juntou, sob o título de Exílios, os camponeses brasileiros que vinham procurar trabalho na cidade com os habitantes dos campos de refugiados em fuga do genocídio de Ruanda. Os movimentos nômades invocados como provas da força explosiva das multidões são, essencialmente, movimentos de populações destruídas pela violência dos Estados-nação ou pela miséria absoluta na qual sua falência os afunda. "Multidões" está, assim como "povo", sujeita a todas as identificações 


\section{Urdimento}

${ }^{6}$ Ibidem., p. 399400. problemáticas. É por isso que no $\mathrm{n}^{\circ} 7$ de Multitudes o 11 de setembro volta aos problemas que floresceram na época em que foi salientado que "o povo" ou "as massas" haviam "desejado o fascismo": as multidões árabes aplaudindo, em nome de Alá, a matança nas Torres Gêmeas eram multidões? Todas as multidões são "verdadeiras” e "legítimas” multidões? Às multidões empíricas opõe-se, novamente, a essência "afirmativa" da multidão. Definitivamente, não basta deslocar-se em massa entre continentes ou correr na velocidade da informática: há sempre um ponto onde a afirmação é assunto de pessoas que organizam juntas uma manifestação, uma recusa. Pode ser o lugar simbólico onde, diante da reunião dos mestres do mundo, se reúnem os manifestantes que sentem a necessidade de dar um aspecto comum à multiplicidade de recusas de seu domínio. Talvez seja a capela parisiense onde fizeram greve de fome os manifestantes que exigiam a obtenção de documentos que lhes permitissem trabalhar e ter uma identidade na França. Os autores de Império são os primeiros a afirmar: à exaltação das topografias extraordinárias sucede na verdade a pergunta: "como as ações da multidão tornam-se políticas? A qual foi respondida, da maneira mais clássica, "quando começa a enfrentar, diretamente e com consciência adequada, as operações repressivas centrais do Império”. E a primeira palavra de ordem que é dada como testemunho dessa consciência é a de "cidadania global", extraída da reivindicação dos "sem-documentos" na França: documentos para todos. ${ }^{6}$ Não saberíamos dizer melhor que a política se joga, em primeiro lugar, nas linhas de partilha de inclusões e exclusões, numa operação de deslocamento das filiações. Mas toda a ambiguidade reside no seguinte: essa reivindicação, dizem os autores, não é irrealista, uma vez que exige o acordo do estatuto jurídico e o estatuto econômico que a internacionalização da produção capitalista também exige. Mas podemos entender este acordo discordante de duas maneiras: ou como a exposição política da lacuna entre o "internacionalismo" da produção exigido pelo lucro capitalista e o "nacionalismo" da ordem jurídico-estatal que assegura as condições de exploração, ou seja, como contradição manifesta do que exige a ordem mundial; ou a entendemos como a afirmação de uma universalidade imanente à ostentação do Império que "contém" as multidões. Ou consideramos as multidões como processos de subjetivação política e questionamos a relação entre os lugares e as formas desses processos; ou então as consideramos, em modo metapolítico, como o próprio nome do poder que anima o todo, arriscando a identificá-lo com algum desejo inconsciente do Ser que nada quer. O pensamento das multidões não escapa às alternativas que encontra, geralmente, o pensamento dos sujeitos políticos. 